\title{
Review
}

Wiebke Solass*, Philipp Horvath, Florian Struller, Ingmar Königsrainer, Stefan Beckert, Alfred Königsrainer, Frank-Jürgen Weinreich and Martin Schenk

\section{Functional vascular anatomy of the peritoneum in health and disease}

DOI 10.1515/pap-2016-0015

Received August 8, 2016; accepted August 30, 2016

\begin{abstract}
The peritoneum consists of a layer of mesothelial cells on a connective tissue base which is perfused with circulatory and lymphatic vessels. Total effective blood flow to the human peritoneum is estimated between 60 and $100 \mathrm{~mL} / \mathrm{min}$, representing $1-2 \%$ of the cardiac outflow. The parietal peritoneum accounts for about $30 \%$ of the peritoneal surface (anterior abdominal wall $4 \%$ ) and is vascularized from the circumflex, iliac, lumbar, intercostal, and epigastric arteries, giving rise to a quadrangular network of large, parallel blood vessels and their perpendicular offshoots. Parietal vessels drain into the inferior vena cava. The visceral peritoneum accounts for $70 \%$ of the peritoneal surface and derives its blood supply from the three major arteries that supply the splanchnic organs, celiac and superior and inferior mesenteric. These vessels give rise to smaller arteries that anastomose extensively. The visceral peritoneum drains into the portal vein. Drugs absorbed are subject to firstpass hepatic metabolism. Peritoneal inflammation and cancer invasion induce neoangiogenesis, leading to the development of an important microvascular network. Anatomy of neovessels is abnormal and characterized by large size, varying diameter, convolution and blood extravasation. Neovessels have a defective ultrastructure: formation of large "mother vessels" requires degradation of venular and capillary basement membranes. Mother vessels give birth to numerous "daughter vessels". Diffuse neoangiogenesis can be observed before appearance of macroscopic peritoneal metastasis. Multiplication of the peritoneal capillary surface by neoangiogenesis
\end{abstract}

*Corresponding author: Wiebke Solass, Institute of Pathology, Medical School Hannover, Hannover, Germany,

E-mail: wiebke.solass@t-online.de

Philipp Horvath, Florian Struller, Ingmar Königsrainer, Stefan

Beckert, Alfred Königsrainer, Frank-Jürgen Weinreich, Martin

Schenk, Department of General, Visceral and Transplant Surgery, Eberhard-Karls-Universitat Tubingen Medizinische Fakultat,

Tuebingen, Germany surface increases the part of cardiac outflow directed to the peritoneum.

Keywords: anatomy, peritoneum, vascular anatomy, vessel

\section{Introduction}

Peritoneal diseases (such as peritonitis or peritoneal metastasis) are common and often result in life-threatening conditions [1]. However, investigations on pathophysiology of these diseases are relatively rare, at least when the numbers are compared to diseases affecting other organs. The peritoneal circulation has not been a field investigated by too many researchers. Many articles have been published decades ago and it is extraordinarily difficult for the circulatory scholar interested in the peritoneum - both in health and disease - to get an overview on this research topic. The aim of the present review is to prevent this neglected area from remaining neglected. The focus of this review is on functional aspects of the vascular anatomy of the peritoneum in health and disease - more than some basic aspects of this anatomy. Examples are taken from clinical practice to highlight the relevance of peritoneal vascularization in natural history of disease, and for designing effective therapeutic strategies.

\section{Surface of the peritoneum}

The abdominal cavity is the largest serous cavity of the human body. The total surface area of the peritoneum in adults approximates the surface area of skin $\left(1.5-2 \mathrm{~m}^{2}\right)$ [2]. However, the exposed part is only a fraction of the total surface of the peritoneum and can be further reduced as a result of adhesions or prior abdominal surgery $[3,4]$. The visceral peritoneum represents about $70 \%$ of the total peritoneal surface $[5,6]$. The anterior abdominal wall of humans comprises less than $4 \%$ of the peritoneal surface [7]. 
Vascular anatomy of the peritoneum

The peritoneum consists of a layer of mesothelial cells on a connective tissue base which is perfused with circulatory and lymphatic vessels. Numerous blood capillaries and few arterioles and venules are observed in the submesothelial layer [8]. Total blood flow to the peritoneum cannot be directly measured due to the diffuse nature of its tissue and its vasculature. However, estimates of effective peritoneal perfusion have been obtained using gas clearance techniques. In the rabbit, peritoneal blood flow was estimated to range between 2.5 and $6.2 \mathrm{~mL} / \mathrm{min}$ per $\mathrm{kg}$ body weight [9]. Figure 1 shows the distribution of the splanchnic blood flow to different abdominal organs and to the peritoneum in the cat.

The parietal peritoneum is perfused by the vessels of the abdominal wall (anterior abdominal wall and flanks) and directly from the abdominal aorta (posterior aspect of the peritoneum). Specifically, arterial blood supply to the parietal peritoneum and underlying musculature arises from the circumflex, iliac, lumbar, intercostal, and epigastric arteries. In the cat, parietal peritoneum blood flow is $6.2 \pm 1.2 \mathrm{~mL} / \mathrm{min}$ per $100 \mathrm{~g}$ tissue, representing $2 \%$ of the splanchnic blood flow or $0.5 \%$ of the cardiac output [10]. The parietal peritoneum drains into the inferior vena cava.

The visceral peritoneum derives its blood supply from the three major arteries that supply the splanchnic organs, celiac and superior and inferior mesenteric.

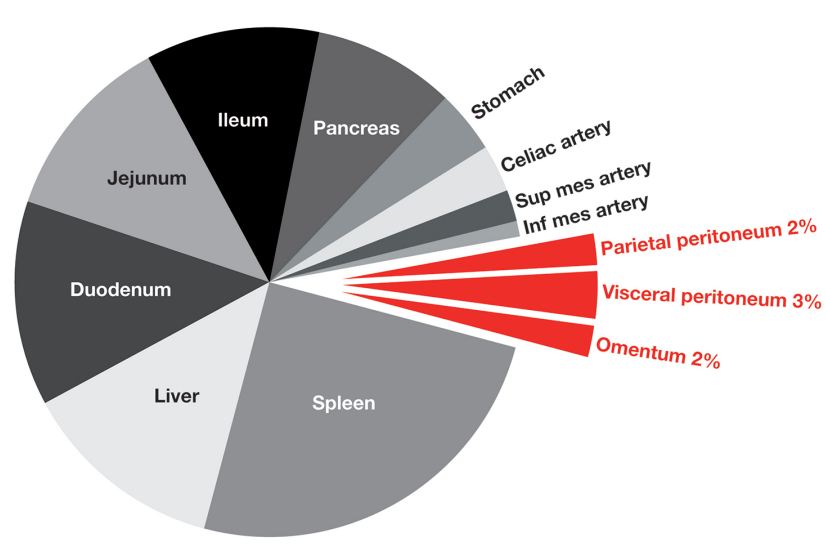

Figure 1: Splanchnic blood flow (cat).

Splanchnic flow represents about $25 \%$ of the cardiac output. Blue slices represent blood flow to various splanchnic organs. Red slices represent blood flow to the peritoneum. Parietal peritoneum blood flow $(6.2 \pm 1.2 \mathrm{~mL} / \mathrm{min}$ per $100 \mathrm{~g}$ tissue $=2 \%)$, visceral peritoneum $(9.7 \pm 1.9 \mathrm{~mL} / \mathrm{min}$ per $100 \mathrm{~g}$ tissue $=3 \%)$, and omentum $(6.3 \pm 0.7$ $\mathrm{mL} / \mathrm{min}$ per $100 \mathrm{~g}$ tissue $=2 \%$ ), represent together $7 \%$ of the splanchnic flow (10) or between 1 and $2 \%$ of the cardiac output.
These vessels give rise to smaller arteries that anastomose extensively. In the cat, the blood flow to the visceral peritoneum was estimated to $9.7 \pm 1.9 \mathrm{~mL} / \mathrm{min}$ per $100 \mathrm{~g}$ tissue, representing about $3 \%$ of the splanchnic blood flow [10]. The visceral peritoneum drains through the inferior mesenteric vein, the superior mesenteric vein and the splenic vein into the portal vein. The portal blood flow to the liver is $1,050 \mathrm{~mL} / \mathrm{min}$, or $21 \%$ of the cardiac minute volume [11]. An importance consequence of the peritoneal outflow into the portal-venous system is that drugs and other solutes that are absorbed through the visceral peritoneum are subject to first-pass hepatic metabolism.

The greater omentum is a fatty structure covered by a double-layer fold of peritoneum which extends from the greater curvature of the stomach to attach to the transverse colon, with a surface area of about $400 \mathrm{~cm}^{2}$. This organ is richly vascularized by the right and left gastro-omental arteries. In the rat, omental blood flow was estimated at $6.3 \pm 0.7 \mathrm{~mL} / \mathrm{min}$ per $100 \mathrm{~g}$ tissue, representing $2 \%$ of the splanchnic blood flow [10]. The right pedicle is dominant with an artery and a vein of $2 \mathrm{~mm}$ diameter. Due to its specific properties of revascularization, the greater omentum is broadly used in reconstructive and plastic surgery for covering defects [12].

Peritoneal blood flow estimates obtained indirectly in peritoneal dialysis patients were than experimental values measured directly in animals [13]. Specifically, measurements in the human being were extrapolated from carbon dioxide diffusion into the peritoneal space and revealed values ranging between $1-2 \mathrm{~mL} / \mathrm{min}$ peritoneal blood flow per kg body weight [14]. It has been estimated that approximately $25 \%$ of cardiac output is directed to the splanchnic vascular bed in normal, resting individuals [15]. Thus, the total abdominal splanchnic blood flow can b estimated at $1,200 \mathrm{~mL} / \mathrm{min}$ at rest, if the parietal peritoneum is not included in the calculation [16]. Altogether, the total effective blood flow to the human peritoneum lies probably between 60 and $100 \mathrm{~mL} / \mathrm{min}$ [9], representing $1-2 \%$ of the cardiac minute volume.

\section{Functional anatomy of the peritoneal microvasculature}

Tissue metabolism required adequate supply with nutrients and oxygen, as well as removal of the degradation products of this metabolism. In mammalians, these supply and clearance functions are provided by a 
microcirculatory network consisting anatomically of arterioles, terminal arterioles, precapillary sphincters, arteriovenous anastomoses, capillaries, postcapillary venules, and venules [17]. Preferential distribution of blood to tissue areas is determined by the small arterioles, which diameter is depending on the local conditions in this specific area. A tissue area can also be bypassed through arteriovenous anastomoses, the blood being then diverted directly from the arterioles into venules. Blood flow through a capillary network is highly variable, can be completely stopped or even sometimes reversing direction $[18,19]$.

Peritoneal microcirculation has an additional function: beside transport of nutrients from and to the cells, peritoneal microvessels regulate physiological interactions between the systemic compartment and the peritoneal cavity. Specific features of this intricate vascular network have been determined by examining the microarchitecture of the peritoneal vessels in animal models (Figure 2). The density distribution of submesothelial microvessels along the different portions of the peritoneum is variable. In the rabbit the mesentery appears to be the most vascularized peritoneal area with $71 \%$ of the total number of observed capillaries. The proportion of diaphragmatic and parietal microvessels to the total examined were $18 \%$ and $11 \%$, respectively [20]. On the mesenteric surface of the peritoneum, abundant arterial and venular arcades were documented. These arcades may function to equalize flow during periods of bowel compression. For the parietal peritoneum, microvasculature was examined experimentally in the cremaster muscle, since the parietal peritoneum extends into the underlying tunica vaginalis testis and since this muscle originates from the abdominal wall
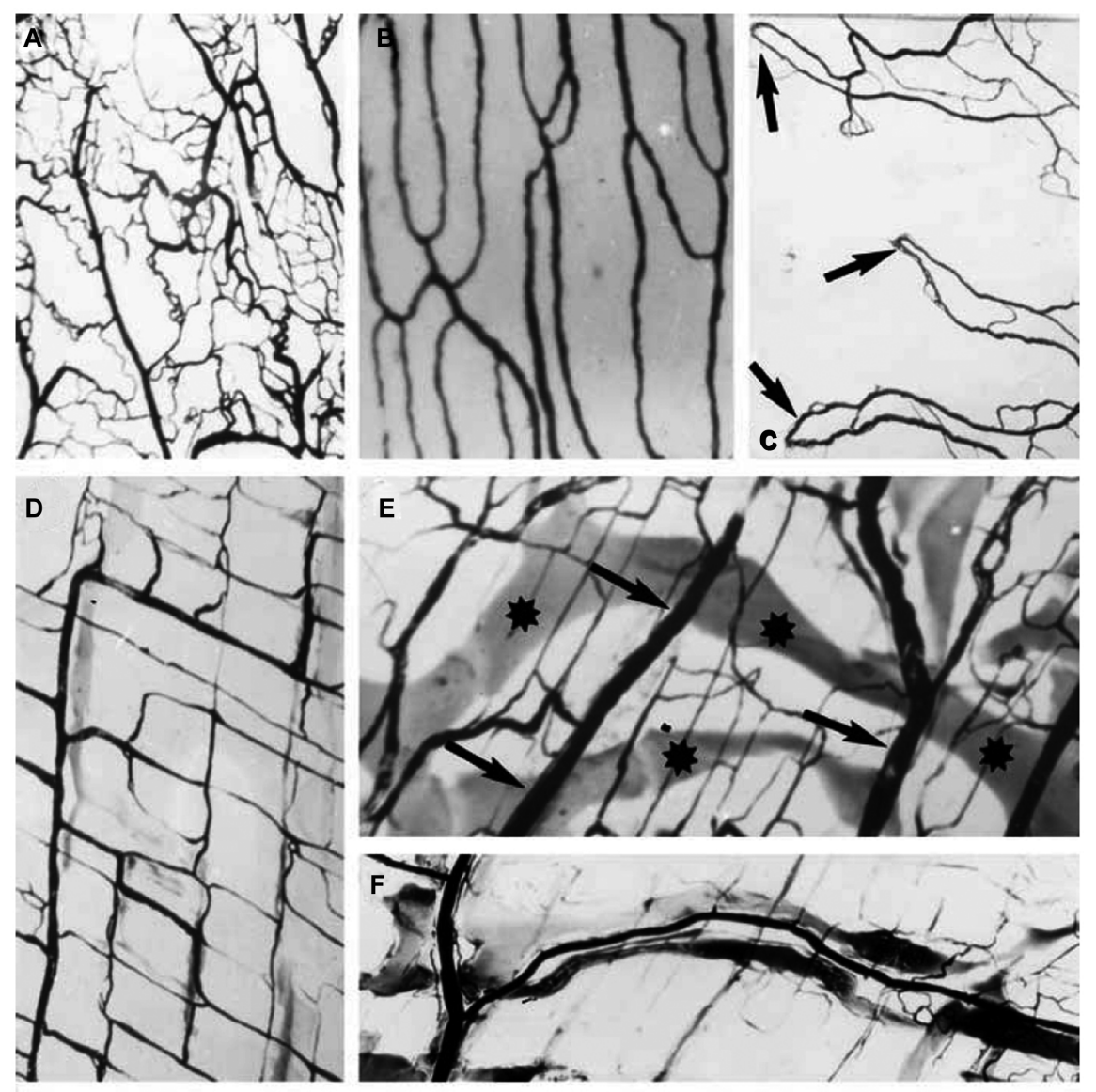

Figure 2: Normal vessels in the submesothelial layer (rodent).

India ink injections demonstrating some characteristic features of the blood supply of mesothelial organs. (A) Visceral pleura. Dense network of small blood vessels. $(\times 12)$. (B) Parietal pleura. Parallel blood vessels. $(\times 24)$; (C) Visceral pericardial sheet. Arterio-venous anastomoses (arrows). $(\times 16)$. (D) Peritoneal side of the diaphragm showing a quadrangular network of large, parallel blood vessels and their perpendicular offshoots. $(\times 24)$. (E) The blood vessels (arrows) are crossed by wide lymphatic vessels $($ stars). $(\times 24)$. (F) The lymphatic vessels follow the course of the blood vessels. $(\times 24)$ (Reproduced from [8]). 
musculature. Specific features of the cremaster microcirculation included the absence of short artery to vein anastomoses and the formation of arteriolar and venular arcades from which capillaries may arise [21-23].

\section{Arterioles}

The arterioles are the major site of microvascular resistance and regulate flow to capillary beds, allowing specific blood distribution to serve that organ's needs. Each nutrient artery entering the subperitoneal space branches several times before the arteries become small enough to be called arterioles, which generally have internal diameters of only 10-15 $\mu \mathrm{m}$. Then the arterioles themselves branch two to five times, reaching even smaller diameters of 5-9 $\mu \mathrm{m}$ at their ends where they supply blood to the capillaries. Arterioles are lined by endothelial cells resting on a basal lamina surrounded by a layer of smooth muscle cells. This highly muscular structure of the arteriolar wall allows their diameters to change manyfold. The distal, ring-shaped smooth muscle layer of an arteriole forms a precapillary sphincter and regulates flow to single capillaries, including complete interruption of the blood flow so that the capillary bed is then bypassed. The most important factor found thus far to affect the degree of opening and closing of the metarterioles and precapillary sphincters is the concentration of oxygen in the tissues [24]. Due to the close proximity of the precapillary sphincters to the target tissue, local conditions (such as the concentrations of nutrients, metabolites, chemotherapeutic agents, $\mathrm{pH}$ etc.) can cause direct effects on the vessels in controlling local blood flow in each small tissue area [24].

\section{Capillaries}

In the peritoneal microvascular peritoneal network as well as in the pleura, solute and fluid exchange occurs mainly in the capillaries [25]. The internal diameter of the capillaries is so small $(4-9 \mu \mathrm{m})$ that erythrocytes have to squeeze to pass the vessel. Anatomically, the capillary wall consists of an endothelium and a basal lamina. These walls are built of single-layer endothelial cells, are very thin $(0.5 \mu \mathrm{m})$ and highly permeable. Since the capillary walls have no intrinsic musculature, they cannot regulate blood flow. The pressure in the systemic capillaries is drops from $35 \mathrm{mmHg}$ in the proximal segment (close to the arterioles) to $10 \mathrm{mmHg}$ in the distal segment (close to the venules). The average hydrostatic pressure in most capillary networks is around $17 \mathrm{mmHg}$. This pressure keeps the plasma clearance through the pores in the capillary walls at a low level, even though nutrients can diffuse easily [26].

\section{Postcapillary venules}

Postcapillary venules are small vessels located just distal to the capillaries. The diameter of the venules is larger $(10-40 \mu \mathrm{m})$ than that of arterioles. The wall of the postcapillary venules consists of endothelial cells supported by a basal lamina surrounded by a layer flat cells (pericytes). In addition, larger venules have a muscular component in their media [27]. Although the venules have a much weaker muscular apparel than the arterioles, these muscles can induce considerable vasoconstriction, since the functional pressure in the venules is much lower than that in the arterioles, so. Permeability of postcapillary venules exhibits significant variability, in particular as a reaction to inflammation. Permeability of postcapillary venules is also influenced by vasoactive agents such as drugs and cytokines. Examples are vascular endothelial growth factor (VEGF), histamine, bradykinin, plateletactivating factor and distinct plasma proteins of the complement system [28-35].

\section{Ultrastructure of peritoneal vessels}

In contrast to the fenestrated endothelium in the intestinal villi, or to the discontinuous endothelium in the liver sinusoid, endothelium is continuous in the peritoneal vessels [36]. The incidence of fenestrated capillaries in human parietal peritoneum appears to be low $(1.7 \%$ of the total number of capillaries) [37]. These differences in the ultrastructure determine how quickly and easy water and solutes can interchange between the tissues and the circulating blood [21], respectively between the peritoneal cavity and the interstitial tissue. Some endothelial cells have a prominent cytofilamentous system. Interdigitations with rare specialized contacts occur between the adjacent endothelial cells. Their basal lamina is not well defined. There are two very small passageways connecting the interior of the capillary with the exterior.

\section{Intracellular clefts}

Intracellular clefts are thin channels located between adjacent endothelial cells. Endothelial cells hold together 
with numerous short ridges of protein attachments traversing the clefs. Fluids can percolate freely around these bridges through the channel. These intercellular clefts have a uniform spacing with a width of 6-7 nm, slightly smaller than the diameter of an albumin molecule. Intracellular clefts represent no more than $1 / 1,000$ of the total surface of the capillary walls but this is enough to ensure a rapid passage of water molecules and most water-soluble ions and small molecules [24].

\section{Plasmalemmal vesicles}

Plasmalemmal vesicles are present within endothelial cells and can move slowly through these cells. They form at the surface of the cell by imbibing small volumes of plasma of extracellular fluid. Experimental data show that plasmalemmal vesicle do not play a significant quantative role in transendothelial transport [24] Some capillaries of the omentum have an endothelium with a significant number of vesicles, corresponding to the rich vesicular system in the overlying mesothelium [8].

\section{Regulation of the splanchnic circulation}

Adequate microvascular perfusion has indeed vital significance for an organism. As most organs and tissues, the peritoneum is able to control its blood flow depending on its own needs. This autoregulation of the splanchnic blood flow is steered by a series of extrinsic and intrinsic factors. Extrinsic factors include general for example systemic blood pressure, heart rate, vascular filling load, autonomic nervous tonus, hormones, circulating neurohumoral agents such as renin and angiotensin. Intrinsic mechanisms include muscular tonus of the vascular walls, $\mathrm{pH}$, degradation products (metabolites), intrinsic nerves and paracrine factors such as Vascular Endothelial Growth Factor (VEGF). A selection of such factors is provided in Table 1. Several overlapping regulatory mechanisms are maintaining splanchnic microcirculation within the physiological range and are preventing radical deviations in tissue perfusion outside this physiological regulation range (reviewed in [38]). Already 50 years ago, it was demonstrated that myogenic autoregulation allows the intestinal smooth musculature and the bowel mucosa to be properly supplied with oxygen and nutrient during digestion [39]. In the colon, these autoregulation mechanisms include control of arteriolar blood flow, whereas pressure changes in the postcapillary venules initiate a direct response on the tone
Table 1: Regulation of peritoneal circulation.

\begin{tabular}{|c|c|c|}
\hline \multirow[t]{2}{*}{ Agent } & \multicolumn{2}{|c|}{ Peritoneal vessels } \\
\hline & Vasodilatation & Vasoconstriction \\
\hline \multicolumn{3}{|l|}{ Physical factors } \\
\hline $\begin{array}{l}\text { Intraperitoneal hydrostatic } \\
\text { pressure }\end{array}$ & & $\mathrm{x}$ \\
\hline Hyperthermia & $\mathrm{X}$ & \\
\hline \multicolumn{3}{|l|}{ Chemical factors } \\
\hline Acidic pH & $\mathrm{X}$ & \\
\hline \multicolumn{3}{|l|}{ Hormones } \\
\hline Angiotensin & & $\mathrm{x}$ \\
\hline Catecholamines & & $\mathrm{x}$ \\
\hline Cholecystokinin & $x$ & \\
\hline Dopamine & $\mathrm{x}$ & \\
\hline Gastrin & $\mathrm{x}$ & \\
\hline Histamine & $\mathrm{x}$ & \\
\hline Vasopressin & & $\mathrm{X}$ \\
\hline \multicolumn{3}{|l|}{ Physiological factors } \\
\hline Food intake & $\mathrm{X}$ & \\
\hline Low-fat food & $\mathrm{x}$ & \\
\hline \multicolumn{3}{|l|}{ Drugs and mediators } \\
\hline Adenosine & $x$ & \\
\hline Hypertonic glucose solutions & $\mathrm{x}$ & \\
\hline Intraperitoneal chemotherapy & $\mathrm{x}$ & \\
\hline Nitric oxide & $\mathrm{x}$ & \\
\hline Peritoneal dialysis solutions & $\mathrm{x}$ & \\
\hline Prostaglandin E1 & $\mathrm{X}$ & \\
\hline \multicolumn{3}{|l|}{ Neurological factors } \\
\hline Increased sympathetic activity & & $x$ \\
\hline $\begin{array}{l}\alpha \text {-Adrenergic blockers } \\
\quad \text { (phenoxybenzamine) }\end{array}$ & $\mathrm{x}$ & \\
\hline
\end{tabular}

of smooth muscles located in precapillary sphincters by chemical interference with intestinal metabolism [40].

\section{Physical factors}

Physical factors such as temperature and pressure have a direct influence on peritoneal circulation. These factors are already used for enhancing the effect of intraperitoneal chemotherapy during Hyperthermic IntraPeritoneal Chemotherapy (HIPEC) [41] and during Pressurized IntraPeritoneal Aerosol Chemotherapy (PIPAC) [42, 43].

\section{Influence of hyperthermia}

Intraperitoneal application of hyperthermia induces a vasodilation of the peritoneal microvasculature. 
Arteriovenous anastomoses connect arterioles directly to the venous plexus and have a rich supply of sympathetic vasoconstrictive fibers and. In response to an increase in body temperature, the withdrawal of sympathetic tone leads to passive dilation of arterioles and arteriovenous anastomoses and enables heat loss by increasing blood flow to the venous plexus [44].

\section{Influence of pressure}

Intraperitoneal application of hydrostatic pressure, for example during laparoscopy, impairs splanchnic blood flow. Higher intraabdominal pressure $(14 \mathrm{mmHg})$ decrease portal and superficial hepatic blood flow and hepatic and intestinal tissue $\mathrm{pH}$. Portal and hepatic venous pressure increased in parallel with the intraabdominal pressure (portal: from 12 to 17 at 7 $\mathrm{mmHg}$ intraabdominal pressure and $22 \mathrm{mmHg}$ at 14 $\mathrm{mmHg}$ intraabdominal pressure; hepatic venous: from 8 to 14 at $7 \mathrm{mmHg}$ intraabdominal pressure and $19 \mathrm{mmHg}$ at $14 \mathrm{mmHg}$ intraabdominal pressure, but the transmural portal and hepatic venous pressures decreased, indicating decreased venous filling. Portal flow was maintained at $7 \mathrm{mmHg}$ but decreased at $14 \mathrm{mmHg}$ from 474 to $395 \mathrm{~mL} / \mathrm{min}$, whereas hepatic arterial flow remained stable. Tissue $\mathrm{pH}$ fell together with portal and hepatic venous $\mathrm{pH}$ (intestinal: from 7.3 to 7.2 ; hepatic $\mathrm{pH}$ : from 7.26 to 7.13 at $14 \mathrm{mmHg}$ ) [45]. In the human patient during $\mathrm{CO}_{2}$ laparoscopy, intra-abdominal pressure elevation from $10 \mathrm{mmHg}$ to $15 \mathrm{mmHg}$ significantly decreased the blood flow in the stomach by $40 \%$ to $54 \%$, the jejunum by $32 \%$, the colon by $44 \%$, the liver by $39 \%$, the parietal peritoneum by $60 \%$, and the duodenum by $11 \%$. Splanchnic blood flow decreased with operative time at a constant intra-arterial pressure [46]. In an experimental nephrectomy model, application of an intraperitoneal pressure during laparoscopy reduced portal flow during laparoscopy by $44 \%$ ( $547 \mathrm{~mL} / \mathrm{min}$ vs. 974$)$ as compared to open surgery.

\section{Influence of chemical factors}

In the animal model, intraperitoneal application of an isotonic lactate solution at a $\mathrm{pH}$ of approximately 8 produced no significant vasoactivity in any microvessel. However, increasing the $[H+]$ of the isotonic lactate solution to match the $\mathrm{pH}$ of the conventional peritoneal dialysis solution ( $\mathrm{pH}$ 5.5) resulted in a significant instantaneous but transient dilation of the arterioles [47].

\section{Influence of physiological factors}

Studies on intestinal absorption in relation to blood flow are rare. Since digestion and absorption are related to increased bowel metabolism, vasodilatation of the splanchnic vasculature is expected follow food ingestion. After implantation of blood flow transducers on the proximal mesenteric artery and hepatic artery in dogs, mesenteric blood flow increased with the quantity of food ingested, and was inversely proportional to the proportion of fat in the food ingested. By contrast, hepatic blood flow was not influenced by these dietary factors. Mesenteric venous outflow was increased by intraluminal of hypertonic glucose solutions, but not by $5 \%$ glucose solutions. This functional hyperemia is mediated by certain gastrointestinal hormones such as gastrin and cholecystokinin. Adenosine is a potent vasodilatator of the mesenteric vascular bed and might be the principal regulator of this autoregulation [48].

Filling volume plays also a major role in splanchnic perfusion. In the dog, hemorrhage reduced peritoneal transport of urea and potassium [49]. Volume therapy is more effective than restoration of blood pressure to obtain adequate mesenteric circulation. However, after hemorrhagic shock in the human patient, a persistent and progressive splanchnic vasoconstriction and hypoperfusion remains despite hemodynamic restoration with intravenous fluid therapy. Adjunctive direct peritoneal resuscitation with a clinical peritoneal dialysis solution instilled into the peritoneal cavity was shown to restore splanchnic tissue perfusion, down-regulate the gut-derived exaggerated systemic inflammatory response, promote early fluid mobilization, and improve overall outcome [50].

\section{Influence of neural factors}

There was a depression of the spontaneous vasomotricity following ganglionic blocade with pentolinium or preganglionic sympathetic blocade effected by spinal anesthesia [51]. Thus, there is a neural control of the peritoneal vascular plexus by sympathetic innervation. Increased sympathetic activity constricts the mesenteric arterioles and capacitance vessels. These responses are mediated by $\alpha$-adrenergic receptors, which are predominant in the mesenteric circulation; however, $\beta$-adrenergic receptors are also present [52]. 


\section{Influence of drugs and solutions}

Numerous enogeneous and exogeneous vasoactive agents have been shown to modify blood flow in the peritoneal microcirculation. A wide variety of drugs, hormones, neurotransmitters and mediators of inflammation alter mesenteric resistance (reviewed in [53]).

\section{Influence of dialysis and non-physiological solutions}

Most commercially available peritoneal dialysis solutions are non-physiologic because of their hypertonicity, high glucose and lactate concentrations, acidic $\mathrm{pH}$, and presence of glucose degradation products [54]. The vasoactive effect of these solutions have been examined in preclinical experiments, in particular in the rodent. These experiments have demonstrated peritoneal dialysis solutions dilate microvessels of visceral peritoneum by endothelium-dependent mechanisms, primarily the nitric oxide (NO) pathway. Specifically, vasodilation in the peritoneal pre-capillary arterioles is induced by adenosine receptor-activated NO release and K(ATP) channel-mediated endothelium hyperpolarization [55]. Most peritoneal dialysis solutions are glucose-based and their hyperosmolality also caused vasodilatation both in the parietal and visceral peritoneum by endothelium-dependent mechanisms [56]. In the animal model, peritoneal dialysis solutions caused a dramatic increase in blood flow to the mesentery, omentum, parietal peritoneum and serosal layer of the intestines but blood flows to the liver, stomach, duodenum, jejunum, ileum, pancreas and spleen were not significantly altered. A hypothesis to explain the selective vasodilation of in the peritoneum is a shorter distance from the peritoneal cavity to microvessels so that diffusion of the vasoactive substances is facilitated [57]. VEGF, an autocrine and paracrine factor, was found in high quantity in peritoneal effluents of peritoneal dialysis patients. Human peritoneal mesothelial cells probably contribute to the intraperitoneal production of VEGF, which in turns induces vasodilation, increases permeability of capillaries and stimulates neoangiogenesis in the subperitoneal space [58].

\section{Vasoconstrictive agents}

Following surgical adrenalectomy in rats, local application of cathecholamines induced vasoconstriction of the directly visualized mesocecal vessels [59]. Using the same preclinical model, adrenergic exclusion induced a persistent vasoconstriction of the mesenteric vascularization and a hyper responsiveness to topically applied epinephrine. The vasocontrictor response that occurs with appropriate stimuli can be prevented by blocking the $\alpha$-adrenergic receptors of the mesenteric vascular bed with phenoxybenzamine. These vessels also contain dopaminergic receptors [48].

\section{Catecholamines}

Large intraperitoneal dose of dopamine in dogs lowered increment in dialysate urea, suggesting a vasoconstriction since blood pressure increased [60]. $\alpha$-adrenergic blockers were added to the dialysis fluid to offset vasoconstriction caused by the dialysis solution: with intraperitoneal phentolamine and intravenous dopamine, peritoneal clearance increased in dogs [61]. Peritoneal clearance also increased in rabbits after intraperitoneal administration of dopamine [62]. The augmented transport is attributed to dopaminereceptor mediated mesenteric vasodilatation and, in part, by general $\alpha$-adrenergic vasoconstriction increasing blood pressure, while mesenteric blood flow is maintained (reviewed in [48]).

\section{Vasopressin and angiotensin}

Vasopressin and angiotensin are potent vasoconstrictor agents acting on the mesenterial circulation [63]. In narcotized dogs, intraperitoneal administration of vasopressin decreased peritoneal clearance of small solutes, consistent with a hormonally-mediated reduction of the splanchnic blood flow [64, 65]. In the rat, angiotensin II decreased the transcapillary ultrafiltration rate by a factor 3. Lymphatic absorption was increased in a dosedependent relationship [66]. In the animal model, blockade of the renin-angiotensin system induced a dilation of the peritoneal vessels after a period of time of 3 days [67].

\section{Vasodilating agents}

Much attention has been devoted to studying the possibilities of increasing blood flow and therefore peritoneal clearance in chronic renal failure patients by systemic or intraperitoneal administration of vasoactive drugs. A similar approach was followed for the management of non-occlusive intestinal ischemia can be managed by early treatment with continuous intravenous high-dose prostaglandin E1 [68]. 


\section{Chemotherapeutic drugs}

Literature on the effect of intraperitoneal chemotherapy on the mesothelium is scarce. Our own experience shows that exposition of the peritoneum to cisplatin and doxorubicin during induces a major systemic inflammatory response that must be caused by the chemical peritonitis, since no other actions are taken [69]. There are other isolated reports on intraabdominal inflammatory reaction following intraperitoneal chemotherapy [70]. Since hyperemia is a landmark of inflammation, it can be reasonably assumed exposition of the peritoneal surface to intraperitoneal chemotherapy causes vasodilatation. In turn, combination of fragile neovessels with drug-induced chemical injury might indeed increase the risk of hemorrhage. There are clinical arguments supporting this hypothesis. For example, intraperitoneal administration of oxaliplatin has been associated with an unacceptable risk of post-exposition hemorrhage, in particular in ovarian cancer. A clinical trial assessing cytoreductive surgery and Hyperthermic IntraPeritoneal Chemotherapy (HIPEC) had to be closed prematurely as there had been an unacceptable rate of re-surgery for peritoneal hemorrhage [71]. Similar observations have been reported by other authors [72-74].

\section{Neoangiogenesis}

In order to grow larger than a few millimeters, peritoneal metastasis must acquire additional nutrient supply through a blood vessel network. When tumors arise in or metastasize to the peritoneum, their growth depends on the invasion of host tissue, allowing the cancer cells close contact with the surface of blood vessels. Therefore, peritoneal metastasis initially associates with and grows preferentially along pre-existing mesenteric vessels (Figure 3), typically at the edge between the small bowel mesenterium and the bowel serosa. Endogenous factors that modulate endothelial cell growth are summarized in Table 2.

VEGF, a key mediator of angiogenesis, has been implicated in the peritoneal dissemination of several cancers (in particular ovarian cancer) and the subsequent

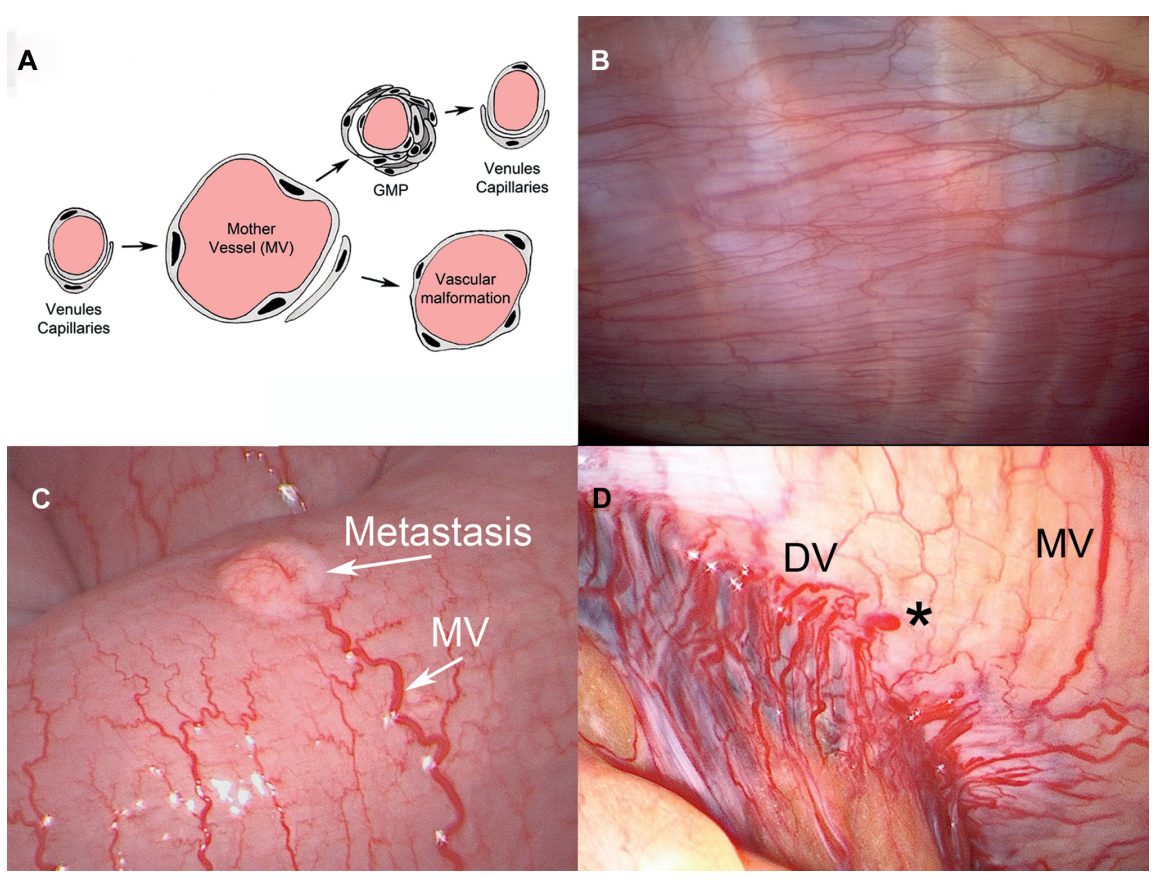

Figure 3: Neoangiogenesis in mesothelial membranes the leaky tumoral neovessels differ from normal blood vessels.

(A) During neoangiogenesis, preexisting normal venules and capillaries evolve within few days into highly abnormal, enlarged "mother" vessels (MV). This production of MV persist as long as VEGF is secreted. MV, with declining VEGF levels, MVs evolve into glomeruloid microvascular proliferation (GMP). In a later stage, vessels return to normal configuration. (B) Intraoperative view of a normal pleura showing a normal microvascular network (C) Intraoperative view showing a $4 \mathrm{~mm}$ large metastasis (arrow) on the visceral peritoneum (small bowel serosa), showing vascular supply by a MV with a diameter 4-5 times larger than normal vessels. (D) Network of neovessels (MV and daughter vessels: DV) showing vascular malformations: various diameters, convoluted vessels and extravasation (star). 
Table 2: Endogenous factors that modulate endothelial cell growth (reproduced from [91]).

\begin{tabular}{|c|c|}
\hline Proangiogenetic factors & Antiangiogenetic factors \\
\hline $\begin{array}{l}\text { Vascular endothelial growth } \\
\text { factor (VEGF) }\end{array}$ & Angiostatin \\
\hline $\begin{array}{l}\text { Basic fibroblast growth factor } \\
\text { (bFGF, FGF2) }\end{array}$ & Endostatin \\
\hline Transforming growth factor- $\beta$ & Thrombospondin-1 \\
\hline Transforming growth factor- $\alpha$ & $\begin{array}{l}\text { SPARC (secreted protein, acidic and } \\
\text { rich in cysteine) }\end{array}$ \\
\hline Hypoxia-inducible factor- $1 \beta$ & $\begin{array}{l}\text { Vascular endothelial growth } \\
\text { inhibitor }\end{array}$ \\
\hline \multicolumn{2}{|l|}{ Hepatocyte growth factor } \\
\hline \multicolumn{2}{|l|}{ Prostaglandin E2 } \\
\hline \multicolumn{2}{|l|}{$\begin{array}{l}\text { Platelet-derived endothelial } \\
\text { cell growth factor }\end{array}$} \\
\hline \multicolumn{2}{|l|}{ Angiogenin } \\
\hline \multicolumn{2}{|l|}{ Interleukin- $\beta$} \\
\hline Angiopoietin & \\
\hline
\end{tabular}

development of malignant ascites. Richly vascularized tumor are highly dependent on VEGF-mediated neoangiogenesis. In primary ovarian tumors, VEGF-receptor expression was detected with an overall frequency of $44 \%$ and was mostly located in the vascular wall and across the stroma [75].

Peritoneal tumors express large amounts of VGEF that typically spill into plasma and ascites fluid in the highpicogram to low-nanogram per $\mathrm{ml}$ range. This explains why diffuse angiogenesis is already observed at an early stage of peritoneal dissemination, when only isolated peritoneal nodes are observed. VEGF initiates a sequence of events including:

- increased vascular permeability;

- extravasation of plasma, fibrinogen and other plasma proteins;

- activation of the clotting system outside the vascular system;

- deposition of an extravascular fibrin gel that serves as a provisional stroma and a favorable matrix for cell migration;

- induction of angiogenesis and arterio-venogenesis;

- subsequent degradation of fibrin and its replacement by "granulation tissue" (highly vascular connective tissue); and, finally,

- vascular resorption and collagen synthesis, resulting in the formation of dense fibrous connective tissue (called "desmoplasia” in cancer).

In peritoneal metastasis, VEGF plays an essential role in generating peritoneal hypersecretion. VEGF secretion by the tumor cells favored the accumulation of fluid in the peritoneal cavity in the animal model and was able to cause a reversible increase of the microvascular permeability without degranulation of mast cells, endothelial cells or further associated lesions [76]. Thus, production of VEGF alone was sufficient to increase capillary protein permeability. In humans, VEGF level was higher in malignant ascites than in cirrhotic ascites and thus confirm the preclinical observations [77]. Other studies have established the proangiogenic role of VEGF and specifically its central role in growth and cell migration of endothelial cells, increased permeability of the endothelial barrier to plasma proteins and alteration of the extracellular matrix. Neovascularization not only increases capillary permeability but also increases the surface of the capillary filter, thus facilitating protein extravasation and modifying oncotic pressure. Thus, VEGF acts on the majority of the factors intervening in the Starling's equation, resulting in an increase of the fluid outflow and accumulation thereof within the peritoneal cavity [78].

The leaky tumoral neovessels differ from normal blood vessels (Table 3 and Figure 4) During neoangiogenesis, preexisting normal venules and capillaries evolve within few days into highly abnormal, enlarged "mother" vessels (reviewed in [79]). Formation of mother vessels require degradation of basal lamina. These membranes are rigid, noncompliant (nonelastic) structures composed of type IV collagen, laminin and proteoglycans, that limit expansion of normal venules and capillaries to about $30 \%$ [80]. Thus, basal lamina

Table 3: Morphological and functional characteristics of the vasculature in normal tissue and in an untreated tumor (reproduced from 93).

\begin{tabular}{|c|c|c|}
\hline Properties & Normal vessel & $\begin{array}{l}\text { Tumoral vessel } \\
\text { (untreated) }\end{array}$ \\
\hline Global morphology & Normal & Abnormal, tortuous \\
\hline Pericyte & Normal & Absent or detached \\
\hline Vessel diameter & Normal & Dilated, variable \\
\hline Vascular density & $\begin{array}{l}\text { Normal, } \\
\text { homogeneous } \\
\text { distribution }\end{array}$ & $\begin{array}{l}\text { Abormal, } \\
\text { heterogeneous } \\
\text { distribution }\end{array}$ \\
\hline MVP and IFP & MFP>IFP & $\mathrm{MVP} \sim \mathrm{IFP}$ \\
\hline $\begin{array}{l}\text { Plasma and interstitial } \\
\text { oncotic pressure }\end{array}$ & $P>1$ & $P \sim 1$ \\
\hline $\mathrm{pO}_{2}$ & Normal & Hypoxia \\
\hline
\end{tabular}

MVP, microvascular pressure; IFP, interstitial fluid pressure; $P$, plasma oncotic pressure; I, interstitial oncotic pressure. 
A

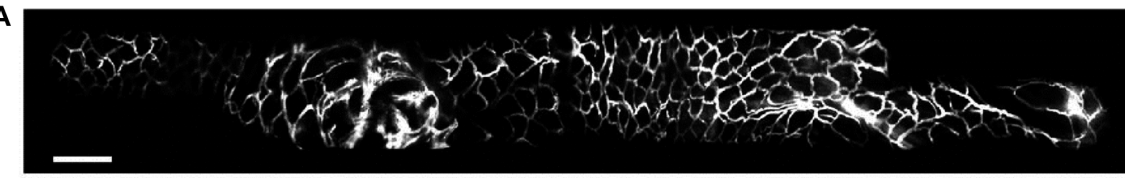

B

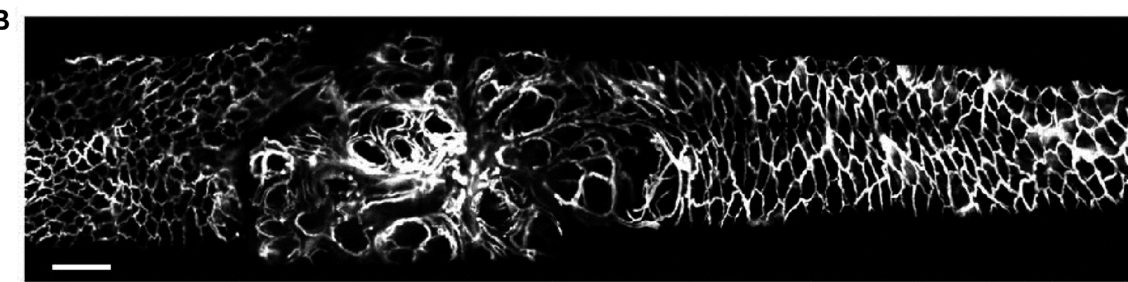

C

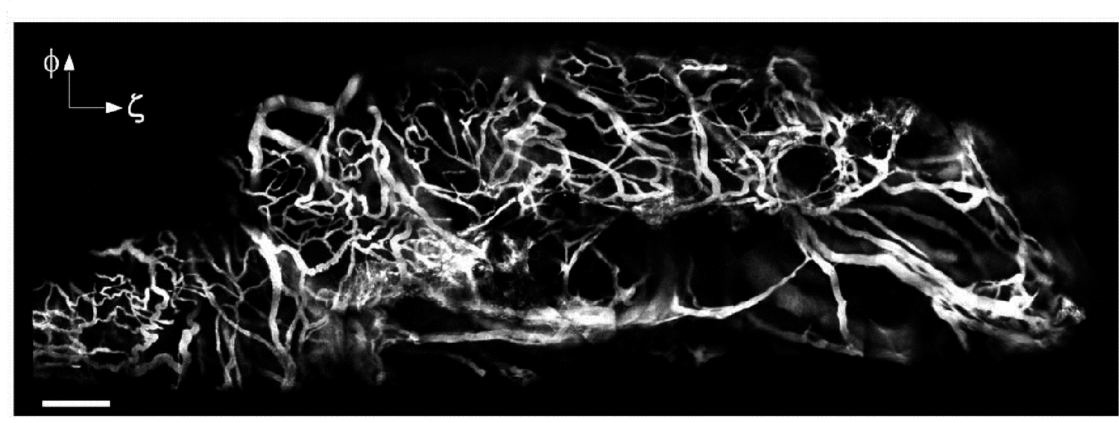

Figure 4: Vascular changes during intestinal tumorigenesis.

Cancer growth was induced by administration of adenoviral Cre into the bowel epithelia of Apc mice to inactivate the Apc gene. (A-C) After making a midline incision, the jejunum was exteriorized outside the abdomen, and opened with a 18 gauge needle. A side-view endoscope was inserted into the bowel. Fluorescence image of colorectal vasculature in a floxed Apc mouse at 11 weeks (A) and 13 weeks (B) after administration of the carcinogenetic vector, and in a large lesion at week 17 (C) in another Cre-treated mouse. Blood vessels are visualized by fluorescence after intravenous injection of FITC-dextran, and show a progressive disorganization in the course of carcinogenesis. Scale bars, $200 \mu \mathrm{m}$. (Reproduced by permission from Macmillan Publishers Ltd: Kim P et al. Nat Methods, Copyright 2010).

must be degraded to allow mother vessels to reach a diameter 4-5 times larger than normal microvessels. In fact, VEGF and metalloproteinases (MMPs) interact in peritoneal metastasis: MMPs, mainly MMP-9 and MMP-2, contribute to the release of biologically active VEGF and consequently to the formation of ascites. Conversely, VEGF inhibition reduces MMP-9 expression while halting ascitic liquid formation [81].

Continuous exposure of the peritoneal serosa to glucose-based dialysis solutions could cause diabetes-like microangiopathy. Longitudinal transport studies in peritoneal dialysis patients suggested the development of a large peritoneal vascular surface area. Neoangiogenesis and thickening of the vascular wall by type IV collagen are remarkably similar with glucose-induced microangiopathy. In the presence of peritoneal sclerosis, the number of vessels per field was higher than in controls, and vascular wall thickening of arterioles and vasodilation of capillaries were found in peritoneal sclerosis compared to all control groups [82]. A similar sequence of events also takes place in a variety of important inflammatory diseases that involve cellular immunity [79].

\section{Enhanced permeability and retention (EPR)}

Tumor blood vessels have a great morphological variability as compared to normal blood vessels. Solid tumors, in particular at the metastatic stage, present characteristic features such as unique vascular architecture, excessive production of vascular mediators and extravasation of macromolecules from blood vessels into the tumor tissue interstitium. Together, these features are called enhanced permeability and retention (EPR) [83]. Anatomy of tumor blood vessels is characterized by oversized gaps between endothelial cells creating a discontinuity in the vascular wall, in particular at the capillary level. Tumor vessels can be contracted, stretched, or constricted. Many solid tumors manifest vascular embolism or vascular clogging, causing localized tumor infarctions and inhomogeneity in blood supply (reviewed in [84]).

Usefulness of narrow-band imaging (NBI) for diagnosis of peritoneal metastasis was assessed during laparoscopy. Intranodular vessels were evaluated for the 
presence of vessel dilatation, vessel tortuousness, vessel heterogeneity and microhemorrhages. NBI was more sensitive for diagnosing peritoneal metastasis than white light imaging [85].

Intravital microscopy (IVM) is also increasingly used for assessing changes in vascular structure and neovascularization at drug target sites such as peritoneal metastasis. IVM also allows determination of a response to therapeutic intervention, for example by measuring response to angiogenesis inhibitors such as $\alpha$-VEGFR antibodies [86]. In peritoneal research, due to the superficial localization of microvessels, high-definition IVM may eventually allow for greater mechanistic understanding of transport processes, particularly extravasation and the role of movement through intercellular gaps, transendothelial cell pores, and transcytosis (reviewed in [87]).

\section{Conclusions}

It is commonly claimed that systemic chemotherapy cannot be effective to treat peritoneal disease because of poor vascularization of the peritoneum [88]. Experimental and clinical measurements have confirmed that only a minimal fraction of the cardiac output reaches the peritoneum. This appears indeed a major limitation for systemic delivery of cytotoxic drugs in the presence of isolated peritoneal disease, assuming that the vast majority of the dose will not reach the target organ but cause organ toxicity, e. g. renal or liver injury.

However, it is not correct to pretend that the peritoneum is poorly vascularized. In fact, blood supply of the peritoneum and of the submesothelial layer is comparable with the supply of other organs when the minute volume is normalized to the tissue weight. Moreover, the values obtained reflect resting conditions in the healthy animal or in peritoneal dialysis patients, but these values can increase considerably under particular physiological conditions, in the case of peritonitis or with the development of peritoneal metastasis. Numerous extrinsic and intrinsic factors control the splanchnic circulation. Several studies have demonstrated that vascularization of the peritoneum is effectively regulated by short-term mechanisms such as vasoconstriction and vasodilatation, under the influence of physical, chemical, neurological, hormonal factors or drugs. These mechanisms allow the peritoneum to regulate blood flow depending on its immediate needs. Vasoconstriction can even completely interrupt blood supply and vasodilatation can multiply blood and oxygen delivery to the tissue in the short term. Regulatory mechanisms acting in the long-term mechanisms such as neoangiogenesis. have also been documented in the peritoneum. These mechanisms can multiply the surface of the submesothelial vascular network. Surgeons used to treat peritoneal metastasis are aware of the rich vascularization of the diseased peritoneum [89]. However, it has been shown that angiogenesis does not imply obligatorily an increased supply of the target tissue with nutrients and oxygen, since neovessels are morphologically largely defective and blood distribution inhomogeneous. Clearly, tumor vascularization is critical for the pathogenesis of of peritoneal metastasis. Because of neoangiogenesis and Enhanced permeability and retention, vascularization also plays a major role for the success of therapy with small molecules, proteins or even with genes [90].

However, the literature on the vascularization of the peritoneum is scarce, in large part older and this area justifies further research. Superficial anatomical location of peritoneal vessels just underneath the single-layered mesothelial membrane allows highly effective in-vivo examination of the different phases of neoangiogenesis and wound healing. Technical means such as laparoscopy, in-vivo confocal microscopy and narrow-band imaging are now available to measure and quantify vascular morphology and function. This combination of favorable anatomical and technological factors offers major methodological opportunities for further research on the functional vascular anatomy of the peritoneum in health and disease.

Author contributions: All the authors have accepted responsibility for the entire content of this submitted manuscript and approved submission.

Research funding: None declared.

Employment or leadership: None declared.

Honorarium: None declared.

Competing interests: The funding organization(s) played no role in the study design; in the collection, analysis, and interpretation of data; in the writing of the report; or in the decision to submit the report for publication.

\section{References}

1. Reymond MA. Pleura and Peritoneum: the forgotten organs. Pleura Peritoneum 2016;1:1-2.

2. Verger C. Peritoneal ultrastructure. In: Nolph KD, editor. Peritoneal dialysis. Boston, MA: Martinus Nijhoff, 1985:95-113.

3. Henderson LW. The problem of peritoneal membrane area and permeability. Kidney Int 1973;3:409-10.

4. Mion CM, Boen ST. Analysis of factors responsible for the formation of adhesions during chronic peritoneal dialysis. Am J Med Sci 1965;250:675-9. 
5. Knapowski J, Feder E, Simon M, Zabel M. Evaluation of the participation of parietal peritoneum in dialysis: physiological morphological and pharmacological data. Proc Eur Dial Trans Assoc 1979;16:155-64.

6. Rubin J, Clawson M, Planch A, Jones Q. Measurements of peritoneal surface area in man and rats. Am J Med Sci 1988;295:453-8.

7. Esperanca MJ, Collins DL. Peritoneal dialysis efficiency in relation to body weight. J Pediatr Surg 1966;1:162-9.

8. Michailova KN, Usunoff KG. Serosal membranes (Pleura, Pericardium, Peritoneum) normal structure, development and experimental pathology. In: Beck FF, Christ B, Clascá F, et al. editors. Advances in anatomy embryologyand cell biology, 2006, 183:1-143.

9. Aune S. Transperitoneal exchange. II. Peritoneal blood flow estimated by hydrogen gas clearance. Scand J Gastroenterol 1970;5:99-104.

10. Granger DN, Ulrich M, Perry MA, Kvietys PR. Peritoneal dialysis solutions and feline splanchnic blood flow. Clin Exp Pharmacol Physiol 1984Sep-Oct;11(5):473-81.

11. Local and humoral control of blood flow by the tissues. In: Guyton AV, Hall JE, editors. Textbook of medical physiology, 11th ed. Philadephia:Elsevier Saunders, 2006:195-203.

12. Micheau P. The greater omentum. Its role in reconstructive plastic surgery. Ann Chir Plast Esthet 1995 Apr;40(2):192-207. Review. French.

13. Gokal R, Khanna R, Krediet RTh, Nolph KD, editors. Textbook of peritoneal dialysis, 2nd ed. Kluwer, 2000:107-33.

14. Nolph KD, Popovich RP, Ghods AJ, Twardowski Z. Determinants of low clearances of small solutes during peritoneal dialysis. Kidney Int 1978 Feb;13(2):117-23.

15. Stephenson RB. Microcirculation and exchange. In: Patton HD, Fuchs AF, Hille B, Scher AM, Steiner R, editors. Textbook of physiology. Philadelphia PA: WB Saunders, 1989:911-23.

16. Bradley SE, Childs AW, Combes B, Cournand A, Wade OL, Wheeler HO. The effect of exercise on the splanchnic blood flow and splanchnic blood volume in normal man. Clin Sci (Lond) 1956 Aug;15(3):457-63.

17. Zweifach BW. The microcirculation of the blood. Sci Am 1959;1:54-60.

18. Richardson. Basic circulatory physiology. Boston, MA: Little, Brown, 1976:101-36.

19. Johnson PC, Wayland H. Regulation of blood flow in single capillaries. Am J Physiol 1967;212:1405-15.

20. Gotloib L, Shostak A, Bar-Sella P, Eiali V. Heterogeneous density and ultrastructure of rabbit's peritoneal microvasculature. Int J Artif Organs 1984;7:123-5.

21. Miller FN. The peritoneal microcirculation. In: Nolph K, editor. Peritoneal dialysis. Boston, MA: Martinus Nijhoff, 1985:51-93.

22. Buez S. An open cremaster muscle preparation for the study of blood vessels by in vivo microscopy. Microvasc Res 1973;5:384-94.

23. Smuje L, Zweifach BW, Intaglietta M. Micropressure and capillary filtration coefficients in single vessels of the cremaster muscle in the rat. Microvasc Res 1970;2:96-110.

24. The microcirculation and the lymphatic system: capillary fluid exchange, interstitial fluim and lymph flow. In: Guyton AV, Hall JE, editors. Textbook of medical physiology, 11th ed. Philadephia:Elsevier Saunders, 2006:181-94.
25. Chambers R, Zwiefach BW. Functional activity of the blood capillary bed, with special reference to visceral tissue. Ann N Y Acad Sci 1946;46:683-94.

26. Chapter 14 Overview of the circulation; medical physics of pressure, flow, and resistance. In: Guyton AV, Hall JE, editors. Textbook of medical physiology, 11th ed. Philadephia: Elsevier Saunders, 2006.

27. Gabella G. Cardiovascular. In: Williams PL, Bannister L, Berry M, Collins P, Dyson M, Dussek J, Ferguson M, editors. Grays anatomy. New York: Churchill Livingstone, 1995, 1466.

28. Granger DN, Richardson PDI, Taylor AE. The effects of iso prenaline and bradykinnin on capillary filtration in the cat small intestine. Br J Pharmacol 1979;67:361-6.

29. Granger DN, Kvietys PR, Wilborn WH, Mortillaro NA, Taylor AE. Mechanisms of glucagon-induced intestinal secretion. Am J Physiol 1980;239:G30-38.

30. Mortillaro NA, Granger DN, Kvietys PR, Rutili G, Taylor AE. Effects of histamine and histamine antagonists on intestinal capillary permeability. Am J Pysiol 1981;240:G381-6.

31. Bjork J, Lindbom L, Gerdin B, Smedegard G, Arfors KE, Benveniste J. PAF (platelet activating factor) increases micro vascular permeability and affects endothelium-granulocyte interactions in microvascular beds. Acta Physiol Scand 1983:119:305-8.

32. Dahlen SE, Bjork J, Hedqvist P, et al. Leukotrienes promote plasma leakage and leukocyte adhesion in postcapillary venules: in vivo effects with relevance to the acute inflammatory response. Proc Natl Acad Sci USA 1981;78:3887-91.

33. Bjork J, Hagli TE, Smedegard G. Microvascular effects of anaphylatoxin C3a and C5a. J Immunol 1985;134:1115-19.

34. Miller FN, Joshua IG, Anderson GL. Quantitation of vasodilatorinduced macromolecular leakage by in vivo fluorescent microscopy. Microvasc Res 1982;24:56-7.

35. Roberts WG, Palade GE. Increased microvascular permeability and endothelial fenestration induced by vascular endothelial growth factor. J Cell Sci 1995;108:2369-79.

36. Wolff JR. Ultrastructure of the terminal vascular bed as related to function. In: Kaley G, Altura BM, editors. Microcirculation. Baltimore, MD: University Park Press, 1977, Vol. I:95-130.

37. Gotloib L, Shostak A, Bar-Sella P, Eiali V. Fenestrated capillaries in human parietal and rabbit diaphragmatic perito neum. Nephron 1985;41:200-2.

38. Parks DA, Jacobson ED. Physiology of the splanchnic circulation. Arch Intern Med 1985;145:1278-81.

39. Jacobson EG. The gastrointestinal circulation. Ann Rev Physiol 1968;30:133-46. Review.

40. Hanson KM, Johnson PC. Pressure-flow relationships in isolated dog colon. Am J Physiol 1967 Mar;212(3):574-8.

41. Lambert LA. Looking up: Recent advances in understanding and treating peritoneal carcinomatosis. CA Cancer J Clin 2015;65:284-98.

42. Solass W, Kerb R, Mürdter T, Giger-Pabst U, Strumberg D, Tempfer C, et al. Intraperitoneal chemotherapy of peritoneal carcinomatosis using pressurized aerosol as an alternative to liquid solution: first evidence for efficacy. Ann Surg Oncol 2014;21:553-9.

43. Jung DH, Son SY, Oo AM, Park YS, Shin DJ, Ahn SH, et al. Feasibility of hyperthermic pressurized intraperitoneal aerosol chemotherapy in a porcine model. Surg Endosc 2015. [Epub ahead of print)]. 
44. Tansey EA, Johnson CD. Recent advances in thermoregulation. Adv Physiol Educ 2015;39:139-48.

45. Windberger UB, Auer R, Keplinger F, Längle F, Heinze G, Schindl M, et al. The role of intra-abdominal pressure on splanchnic and pulmonary hemodynamic and metabolic changes during carbon dioxide pneumoperitoneum. Gastrointest Endosc 1999;49:84-91.

46. Schilling MK, Redaelli C, Krähenbühl L, Signer C, Büchler MW. Splanchnic microcirculatory changes during CO2 laparoscopy. J Am Coll Surg 1997;184:378-82.

47. Zakariael R, Patel AA, Li N, Matheson PJ, Garrison RN. Vasoactive components of dialysis solution. Perit Dial Int 2008 May-Jun;28(3):283-95.

48. Lameire N, Van Biesen W, Hirszel P, Bogaert M. Pharmacological alterations of peritoneal transport rates and pharmacokinetic in peritoneal dialysis. The peritoneal microcirculation in peritoneal dialysis. In: Gokhal R, et al. editors. Textbook of peritoneal dialysis, 2nd ed. Kluwer, 2007:193-251.

49. Erbe RW, Greene Jr JA, Weller JM. Peritoneal dialysis during hemorrhagic shock. J Appl Physiol 1967 Jan;22(1):131-5.

50. Zakariael R, Li N, Garrison RN. Mechanisms of direct peritoneal resuscitation-mediated splanchnic hyperperfusion following hemorrhagic shock. Shock 2007 Apr;27(4):436-42.

51. Baez S, Kopman AF, Orkin LR. Microvascular hypersensitivity subsequent to chemical denervation. Circ Res 1967;20:328-37.

52. Swan KG, Reynolds DG. Adrenergic mechanisms in canine mesenteric circulation. Am J Physiol 1971 Jun;220(6):1779-85.

53. White R, Grangier DN. The peritoneal microcirculation in peritoneal dialysis. In: Gokhal R, et al. editors. Textbook of peritoneal dialysis, 2nd ed. Kluwer, 2007:107-33.

54. Mortier S, De Vriese AS, Van de Voorde J, Schaub TP, PasslickDeetjen J, Lameire NH. Hemodynamic effects of peritoneal dialysis solutions on the rat peritoneal membrane: role of acidity, buffer choice, glucose concentration, andglucose degradation products. J Am Soc Nephrol 2002 Feb;13(2):480-9.

55. Zakariael R, Althani A, Fawzi AA, Fituri OM. Molecular mechanisms of peritoneal dialysis-induced microvascular vasodilation. Adv Perit Dial 2014;30:98-109.

56. Zakariael R, Althani A, Fawzi AA, Fituri OM. Hyperosmolalitymediated peritoneal microvascular vasodilation is linked to aquaporin function. Adv Perit Dial 2014;30:63-74.

57. Miller FN, Nolph KD, Harris PD, Rubin J, Wiegman DL, Joshua IG, et al. Microvascular and clinical effects of altered peritoneal dialysis solutions. Kidney Int 1979 Jun;15(6):630-9.

58. Mandl-Weber S, Cohen CD, Haslinger B, Kretzler M, Sitter T. Vascular endothelial growth factor production and regulation in human peritoneal mesothelial cells. Kidney Int 2002;61:570-8.

59. Altura BM. Role of glucocorticoids in local regulation of blood flow. Am J Physiol 1966;211:1393-7.

60. Gutman RA, Nixon WP, McRae RL, Spencer HW. Effect of intraperitoneal and intravenous vasoactive amines on peritoneal dialysis: study in anephric dogs. Trans Am Soc Artif Intern Organs 1976;22:570-4.

61. Henderson LW, Parker HR, Schroeder JP, Frigon R, Sanfelippo $M L$. Continuous low flow hemofiltration with sorbent regeneration of ultrafiltrate. Trans Am Soc Artif Intern Organs 1978;24:178-84.

62. Hirszel P, Lasrich M, Maher JF. Augmentation of peritoneal mass transport by dopamine: comparison with norepinephrine and evaluation of pharmacologic mechanisms. J Lab Clin Med 1979;94:747-54.

63. Rocha E, Silva Jr M, Rosenberg M. The release of vasopressin in response to haemorrhage and its role in the mechanism of blood pressure regulation. J Physiol 1969 Jun; 202(3):535-57.

64. Hare HG, Valtin H, Gosselin RE. Effet of drugs on peritoneal dialysis in the dog. Pharmacol Exp Ther 1964;145:122-9.

65. Henderson LW, Kintzel JE. Influence of antidiuretic hormone on peritoneal membrane area and permeability. J Clin Invest 1971;50:2437-43.

66. Go M, Kumano K, Sakai T. Effect of angiotensin II(AII) on peritoneal transport during peritoneal dialysis in rat. Nihon Jinzo Gakkai Shi 1992;34:921-9.

67. Ishida Y, Tomori K, Nakamoto H, Imai H, Suzuki H. Effects of antihypertensive drugs on peritoneal vessels in hypertensive dogs with mild renal insufficiency. Adv Perit Dial 2003;19:10-14.

68. Mitsuyoshi A, Obama K, Shinkura N, Ito T, Zaima M. Survival in nonocclusive mesenteric ischemia: early diagnosis by multidetector row computed tomography and early treatment with continuous intravenous high-dose prostaglandin E(1). Ann Surg 2007;246:229-35.

69. Nadiradze G, Giger-Pabst U, Zieren J, Strumberg D, Solass W, Reymond MA. Pressurized intraperitoneal aerosol chemotherapy (PIPAC) with low-dose cisplatin and doxorubicin in gastric peritoneal metastasis. J Gastrointest Surg 2016;20:367-73.

70. Lee S. An unusual intra-abdominal inflammatory reaction to intraperitonealchemotherapy. Minn Med 2015 Aug; 98(8):37-8.

71. Pomel C, Ferron G, Lorimier G, Rey A, Lhomme C, Classe JM, et al. Hyperthermic intra-peritoneal chemotherapy using oxaliplatin as consolidation therapy for advanced epithelialovarian carcinoma. Results of a phase II prospective multicentre trial. CHIPOVAC study. Eur J Surg Oncol 2010;36:589-93.

72. Marcotte E, Sideris L, Drolet P, Mitchell A, Frenette S, Leblanc G, et al. Hyperthermic intraperitoneal chemotherapy with oxaliplatin for peritoneal carcinomatosis arising from appendix: preliminary results of a survival analysis. Ann Surg Oncol 2008;15:2701-8.

73. Ceelen WP, Peeters M, Houtmeyers P, Breusegem C, DeSomer F, Pattyn P. Safety and efficacy of hyperthermic intraperitoneal chemoperfusion with high-dose oxaliplatin in patients with peritonealcarcinomatosis. Ann Surg Oncol 2008;15:535-41.

74. Fagotti A, Paris I, Grimolizzi F, et al. Secondary cytoreduction plus oxaliplatin-based HIPEC in platinum-sensitive recurrent ovarian cancer patients: a pilot study. Gynecol Oncol 2009;113:335-40.

75. Wimberger P, Chebouti I, Kasimir-Bauer S, Lachmann R, Kuhlisch E, Kimmig R, et al. Explorative investigation of vascular endothelial growth factor receptor expression in primary ovarian cancer and its clinical relevance. Gynecol Oncol 2014;133:467-72.

76. Dvorak HF, Brown LF, Detmar M, Dvorak AM. Vascular permeability factor/vascular endothelial growth factor, microvascular hyperpermeability, and angiogenesis. Am J Pathol 1995;146:1029-39. 
77. Zebrowski BK, Liu W, Ramirez K, Akagi Y, Mills GB, Ellis LM. Markedly elevated levels of vascular endothelial growth factor in malignant ascites. Ann Surg Oncol 1999;6:373-8.

78. Tamsma JT, Keizer HJ, Meinders AE. Pathogenesis of malignant ascites: Starling's law of capillary hemodynamics revisited. Ann Oncol 2001;12:1353-7. Review.

79. Dvorak HF. Tumors: wounds that do not heal-redux. Cancer Immunol Res 2015 Jan;3(1):1-11.

80. Chang SH, Kanasaki K, Gocheva V, Blum G, Harper J, Moses MA, et al. VEGF-A induces angiogenesis by perturbing the cathepsincysteine protease inhibitor balance in venules, causing basement membrane degradation and mother vessel formation. Cancer Res 2009;69:4537-44.

81. Masoumi Moghaddam S, Amini A, Morris DL, Pourgholami MH. Significance of vascular endothelial growth factor in growth and peritoneal dissemination of ovarian cancer. Cancer Metastasis Rev 2012;31:143-62.

82. Mateijsen MA, van der Wal AC, Hendriks PM, Zweers MM, Mulder J, Struijk DG, et al. Vascular and interstitial changes in the peritoneum of CAPD patients with peritoneal sclerosis. Perit Dial Int 1999;19:517-25.

83. Matsumura Y, Maeda H. A new concept for macromolecular therapeutics in cancer chemotherapy: mechanism of tumoritropic accumulation of proteins and the antitumor agent SMANCS. Cancer Res 1986;46:6387-92.

84. Maeda H, Tsukigawa K, Fang JA. Retrospective 30 years after discovery of the enhanced permeability and retention effect of solid tumors: next-generationchemotherapeutics and photodynamic therapy-problems, solutions, and prospects. Microcirculation 2016;23:173-82.
85. Kikuchi H, Kamiya K, Hiramatsu Y, Miyazaki S, Yamamoto M, Ohta $\mathrm{M}$, et al. Laparoscopic narrow-band imaging for the diagnosis of peritoneal metastasis in gastric cancer. Ann Surg Oncol 2014;21:3954-62.

86. Tolaney SM, Boucher Y, Duda DG, Martin JD, Seano G, Ancukiewicz M, et al. Role of vascular density and normalization in response to neoadjuvant bevacizumab and chemotherapy in breast cancer patients. Proc Natl Acad Sci U S A 2015;112:14325-30.

87. Miller MA, Weissleder R. Imaging the pharmacology of nanomaterials by intravital microscopy: Toward understanding their biological behavior. Adv Drug Deliv Rev 2016. [Epub ahead of print]. Review.

88. Trenta P, Giovannoni S, Risi E, The CE. Role of systemic chemotherapy. In: Di Giorgio A, Pinto E, editors. Treatment of peritoneal surface malignancies. State of the art and perspectives. Springer, 2015.

89. De Bree E, Tsiftsis D. Principles of perioperative intraperitoneal chemotherapy for peritoneal carcinomatosis. In: GonzalezMoreno S, editor. Advances in peritoneal surface oncology. Springer, 2007.

90. Ottolino-Perry K, Tang N, Head R, Ng C, Arulanandam R, Angarita FA, et al. Tumor vascularization is critical for oncolytic vaccinia virus treatment of peritoneal carcinomatosis. Int J Cancer 2014;134:717-30.

91. Rippe B. Peritoneal angiogenesis in response to dialysis fluid. Contrib Nephrol 2009;163:60-6.

92. Jain RK. Normalization of tumor vasculature: an emerging concept in antiangiogenic therapy. Science 2005;307:58-62. Review. 